\title{
The Effects of Intermittent Insulin Therapy on the Autonomic Neuropathy in the Streptozotocin Diabetic Rat
}

\author{
GEORGE MONCKTON and ENID PEHOWICH
}

SUMMARY: An ultrastructural study of the dorsal sympathetic ganglia, chain, and myenteric plexus is described in the streptozotocin diabetic rat after intermittent insulin treatment. The observations described cover the first two weeks following induction of diabetes in which insulin was administered subcutaneously twice daily. Significant regenerative changes were seen with marked axonal sprouting noted at three days. Degenerative changes were seen to be less severe than those in untreated animals. It is concluded that the improvement in the neuropathic changes with insulin treatment supports a transient primary role of the streptozotocin in causing the neuropathy - but that the subsequent improvement seems to be related to the partial control of the diabetes.

RÉSUMÉ: Nous décrivons une étude ultrastructurale du ganglion sympathique dorsal, de la chaîne ganglionnaire et du plexus myentérique chez le rat rendu diabétique par la streptozotocine et traité à l'insuline de façon intermittente. L'insuline fut administrée de façon sous-cutanée deux fois par jour et les observations faites sur une période de deux semaines après l'induction du diabète. Des changements régénératifs importants furent observés avec du "sprouting" axonal important dès le $3 e$ jour. Ces changements étaient de moindre importance que chez les animaux non traités. Cette amélioration avec l'insuline supporte un rôle primaire pour la streptozotocine dans la genèse de la neuropathie mais l'amélioration subséquente semble être reliée au contrôle partiel du diabète.

From the Department of Medicine (Neurology) University of Alberta, Edmonton, Alberta, Canada

Reprint Requests to: Dr. George Monckton, Neurology Unit, 9-101 Clinical Sciences Building, The University of Alberta, 11282 - 84 Avenue, Edmonton, Alberta T6G 2G3.

Supported by a grant from the Canadian Diabetic Association.

\section{INTRODUCTION}

In a previous paper we were able to show that an autonomic neuropathy occurs in the streptozotocin diabetic rat (Monckton \& Pehowich, 1980). This neuropathy which shows widespread involvement of the dorsal sympathetic ganglia, chain, and Auerbach's plexus, is discernible within 24 hours of the onset of diabetes. In the peripheral nervous system a reduction of nerve conduction velocity has been observed in both the alloxan and streptozotocin diabetic rat (Eliasson, 1964, 1969; Seneviratne and Peiris, 1969; Greene et al, 1975; Jakobsen 1976, a \& b). The impairment of nerve conduction has been shown by Jakobsen (1979) to be preventable or reversible by treatment with intermittent insulin. Accordingly, it was decided to undertake a study of a series of rats treated with intermittent subcutaneous insulin to produce at least partial control of the diabetes in order to determine whether the improved diabetic and metabolic state would ameliorate the severity of the neuropathy.

\section{METHODS:}

Female Wistar albino rats six weeks of age weighing between 125 and 150 grams were used in this study. Three rats were used as controls and 9 were rendered diabetic by intravenous injection (foot vein) of streptozotocin (Upjohn) in doses of $80 \mathrm{mg} / \mathrm{kg}$. The control and diabetic animals were treated similarly and maintained on regular Purina rat chow with water ad libitum. In order to avoid severe metabolic and diabetic disturbances, insulin treatment was started six hours after injection of streptozotocin at which time the blood glucose levels were in the diabetic range. Thereafter, blood and urine glucose levels were determined twice daily. Weight and urine output were recorded daily. From this information, an appropriate dose of insulin (NPH pork insulin) ranging from 0.5 to 3 units was administered subcutaneously morning and evening.

At three, seven, and fourteen days the animals were injected intraperitoneally with sodium thiopental in lethal doses. As soon as the animals were unconscious segments of jejunum were removed for fixation. Twenty $\mathrm{ml}$ of Tyrode buffer at $\mathrm{pH} 7.4$ was perfused through an intra-aortic catheter followed by $200 \mathrm{ml}$ of $2 \%$ glutaraldehyde in $0.1 \mathrm{M}$ cacodylate buffer, $\mathrm{pH}$ 7.4. This perfusate was followed by $20 \mathrm{ml}$ Tyrode buffer as above, then by $40 \mathrm{ml} 1 \%$ osmium tetroxide in phosphate buffer, $\mathrm{pH}$ 7.4. Dissection and removal of the sympathetic chains and ganglia were then performed. Following post-fixation in osmium, the material was dehydrated and embedded in Epon 812 (Luft, 1961).

Sections of the sympathetic chain below the fifth dorsal ganglion were cut starting $4 \mathrm{~mm}$ below the border of the fifth ganglion. Sections were cut so that 5 one micron serial sections and 10 thin serial sections were cut at five micrometer intervals from each millimeter segment of chain. Thin sections were stained with uranyl acetate and lead citrate and then examined and photographed in a Siemen's L-102 electron microscope. From these sections, the cross-sectional diameter of axons and ultrastructural changes were determined.

Sections of jejunum and sympathetic ganglia were examined at the light and EM levels. Measurement of the individual cross-sectional area of 1,000 
axons in each animal was accomplished by using a Zeiss MOP 3 computer tissue analyzer. From these, data histograms and statistical analyses were made.

\section{RESULTS}

The general condition of the rats at the time they were sacrificed was much better than that in our untreated diabetic animals. The daily weights of the rats showed moderate weight gain for both groups of animals. In neither group was the weight gain up to the normal of 4 - 5 grams/day. (Figures 1 a $\&$ b). Blood sugars were determined twice daily and the maximal values recorded for each animal are indicated in Figure 2 which shows all the animals to be diabetic with only partial control of their diabetes.

\section{Morphometric Analysis:}

The accompanying histograms (Figure 3) show the average of axonal cross-sectional areas for three animals in each group - those treated with intermittent insulin, and untreated diabetic rats at three, seven, and fourteen days following induction of diabetes with streptozotocin. The histograms from the treated and untreated groups show a marked shift of fiber distribution to the left which appears maximal at seven days in both groups.' At 14 days, although the median for the treated group is slightly greater, there is a higher percentage of fibers with areas less than $0.4 \mu \mathrm{m}^{2}-$ $41 \%$ in the treated and $26 \%$ in the untreated. In the normal animals there are only $18.9 \%$ of fibers with areas under $0.4 \mu \mathrm{m}^{2}$.

\section{Ultrastructural Observations: Dorsal Sympathetic Chain}

The ultrastructural appearances of the normal dorsal sympathetic chain are shown in Figure 4. At three days the outstanding feature is the great variation of size of the axons with a marked increase in the numbers of axons with areas less than $0.4 \mu \mathrm{m}^{2}$. Some axons show loss of definition with an apparent leaching of stainable material. Loss of microtubules with relative preservation of neurofilaments is notable in many axons. The loss of microtubules appears to be most profound in the central portions of the axons with small numbers remaining in the periphery of some fibers (Figure 5). Some of the smaller axons are noted to have lengthened and tortuous mesaxons. Schwann cell processes appear to be engulfing many of the smaller axons.

At seven days the variation in in- dividual axonal area noted at three days is essentially unchanged. Many axons are present with long and complicated mesaxons. There is widespread loss of microtubules in the majority of axons and those that are present are commonly, but not exclusively, located in the periphery of the axons (Figure 6). Numbers of vesicles of various types are present. Some of these are lysosomes.

At fourteen days the variation in axonal diameters is still present, but there appears to be a suggestion of some increase in numbers of larger axons. The majority of fibers are still in the 0.4 to $0.5 \mu \mathrm{m}^{2}$ range. Many axons appear to have increased numbers of vesicles of various types, some of which appear to have dense cores while others appear to be coated. Lysosomes and dense bodies are also present. Although there are considerable numbers of regenerating axons present there remain some swollen axons with small numbers of microtubules and neurofilaments and a general thinning of axoplasm exhibiting the general appearances of early wallerian degeneration (Figure 7 a). These changes, however, are not as severe as those seen at fourteen days in the untreated animal (Figure $7 \mathrm{~b}$ ). In these animals many more swollen and degenerating axons were seen. $\mathrm{Al}$ -

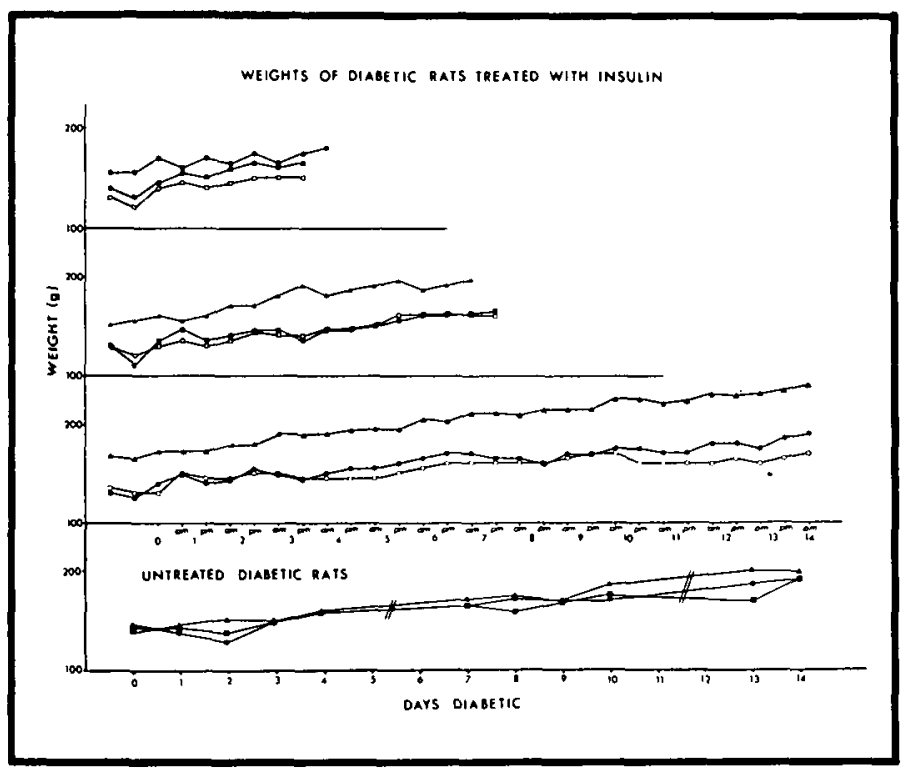

Figure I - (a) Daily weight chart of streptozotocin diabetic rats treated with intermittent subcutaneous insulin. (b) Daily weight chart of untreated streptozotocin diabetic rats.

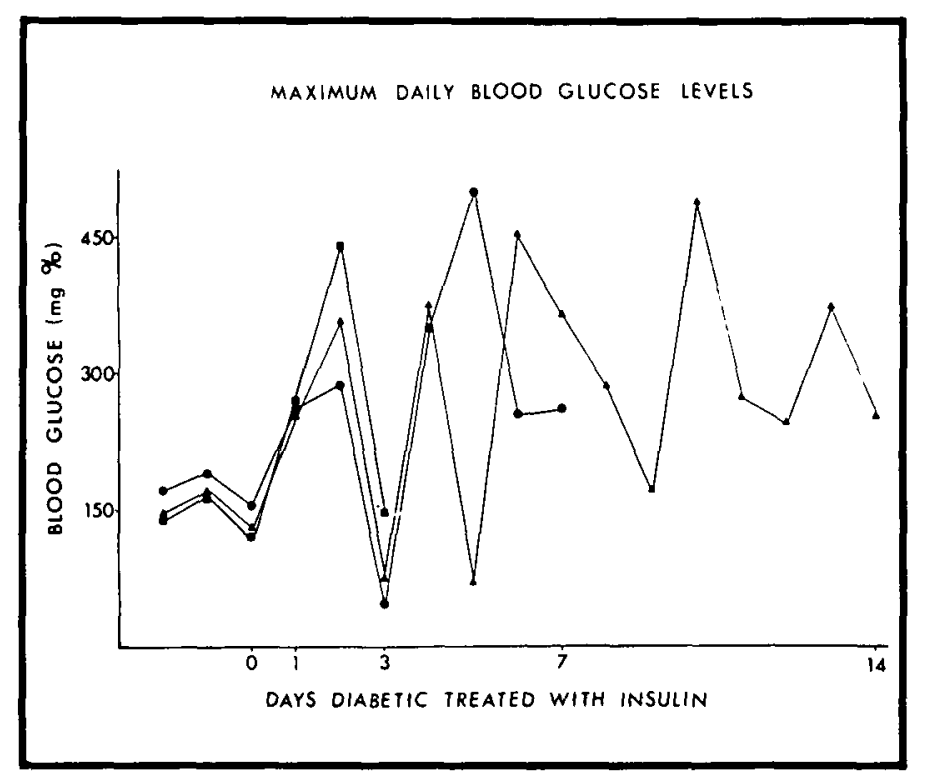

Figure 2 - Graph showing the mean of maximum daily blood sugar of the three animals in each group of rats treated with intermittent insulin. 


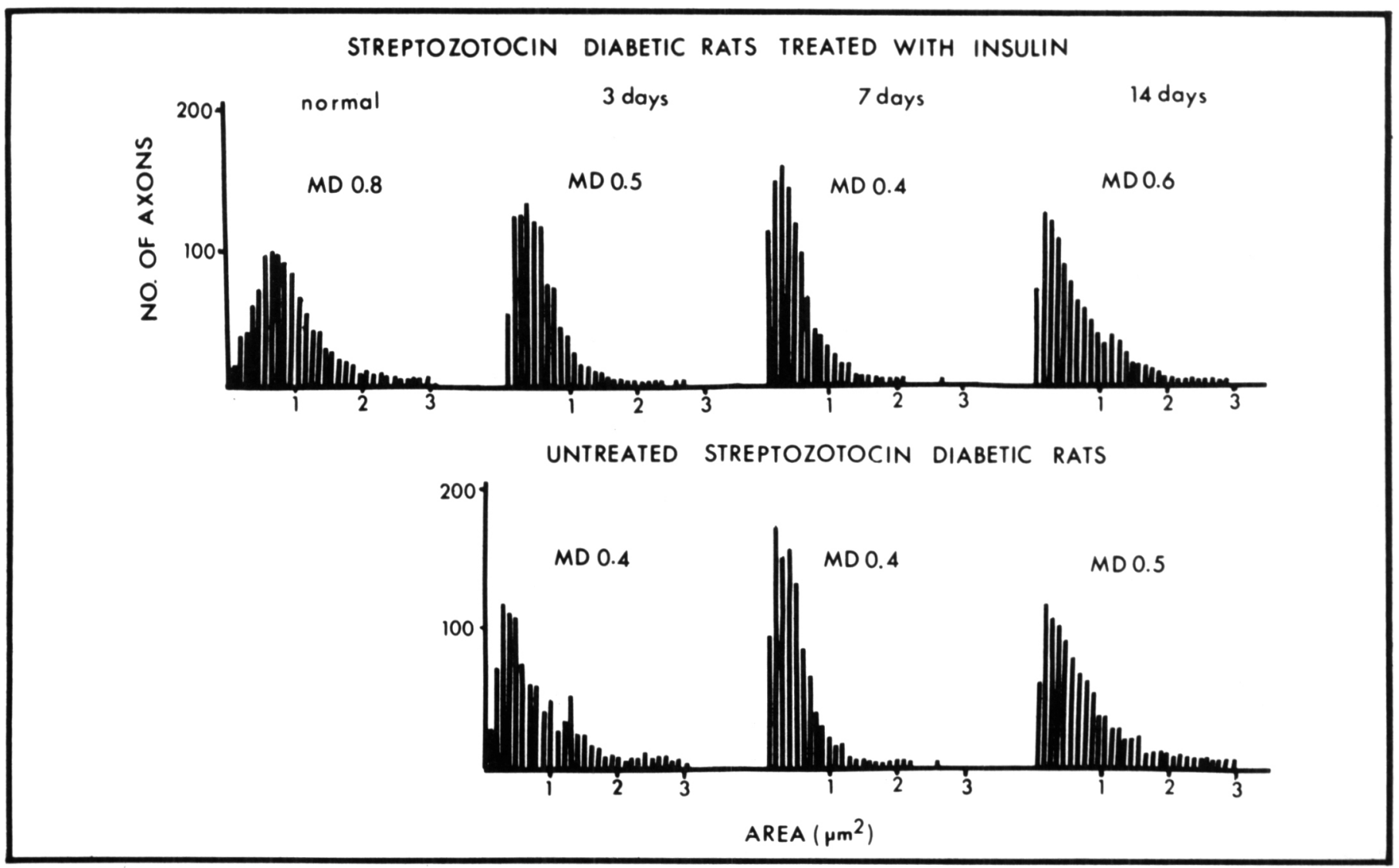

Figure 3 - Histograms showing the distribution of fiber size by the average axonal cross-sectional of streptozotocin diabetic rats either treated with intermittent insulin or untreated. The histograms show axon distribution at three, seven, and fourteen days after induction of diabetes, and were derived by averaging the numbers of axons in each $0.1 / \mu \mathrm{m}^{2}$ bin of three animals. 1,000 axons were measured in each animal.

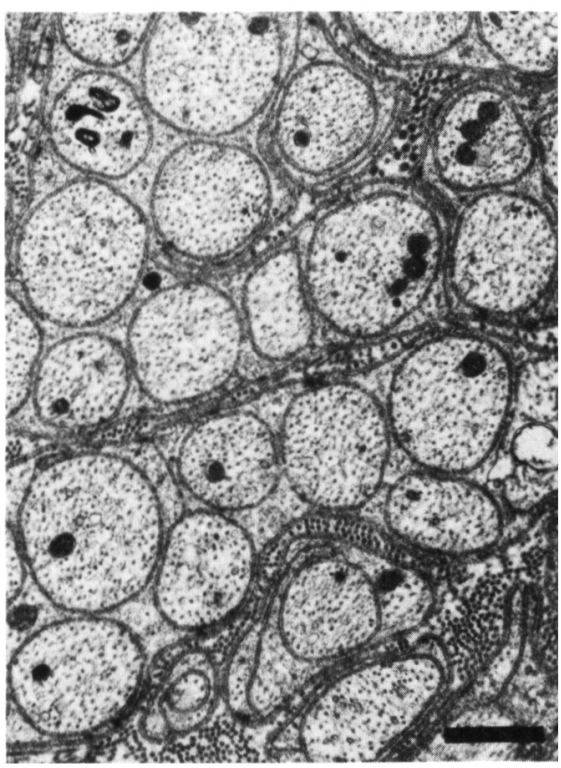

Figure $4-$ Ultrastructural appearances of the normal dorsal sympathetic chain. Bar $=1$ $\mu \mathrm{m}$.

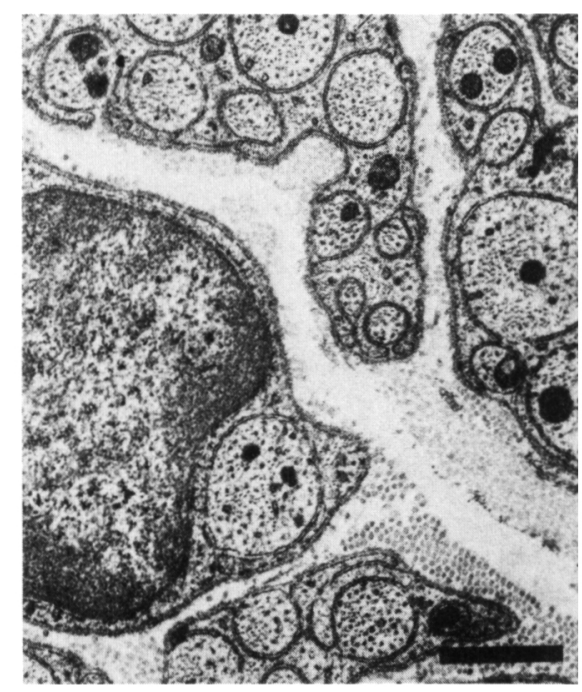

Figure 5 - Cross-section of dorsal sympathetic chain of streptozotocin diabetic rat after three days treatment with intermittent subcutaneous insulin. Some axons show loss of microtubules more severely in the central areas of the axons. Many small axons are shown only partially engulfed by Schwann cell. Bar $=1 \mu \mathrm{m}$

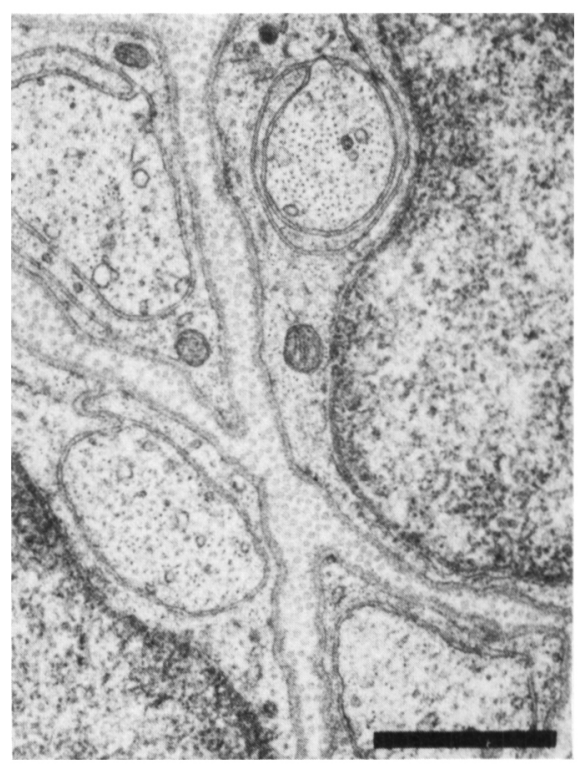

Figure 6 - Dorsal sympathetic chain of streptozotocin diabetic rat after seven days treatment with intermittent subcutaneous insulin. Note long mesaxons and sparse microtubules. $\mathrm{Bar}=1, \mu \mathrm{m}$. 


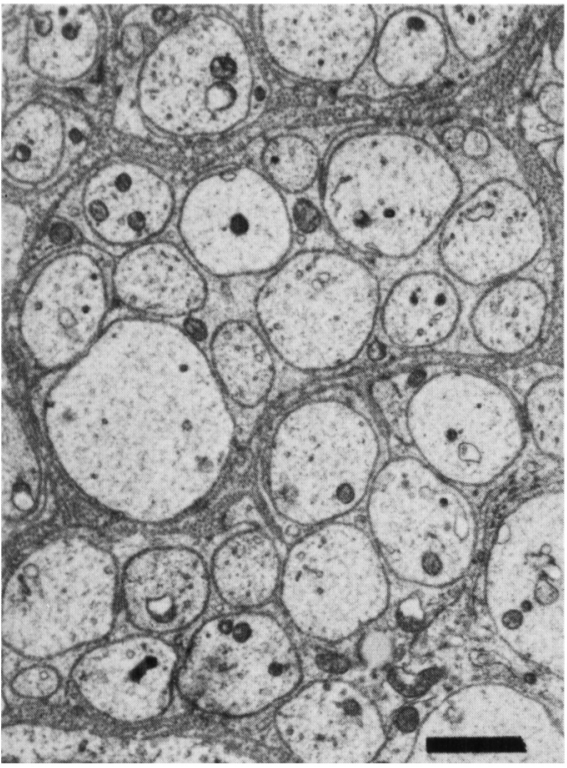

Figure $7(a)$ - Dorsal sympathetic chain of streptozotocin diabetic rat after 14 days treatment with intermittent subcutaneous insulin. Larger degenerating axons are occasionally seen as in this micrograph. Bar $=$ $1 \mu \mathrm{m}$.

though the histograms of treated and untreated animals are quite similar, the ultrastructure shows that there are more intact larger fibers in the treated animals accounting for the broader base of the histogram, whereas, in the untreated group, most of the larger fibers are degenerating.

\section{Ganglion Cells of the Sympathetic Chain}

Examination of sections of the autonomic ganglia at the light level shows essentially no changes at three days. Occasional ganglion cells show some eccentricity of the nucleus and abnormal distribution of Nissl substance. A few refractile bodies are seen in the cytoplasm which are presumed to be lipid laden lysosomes. At seven days the changes become more obvious and generalized. Eccentric nuclei are seen and shrunken chromatolytic nerve cells are present (Figure 8). In the surviving ganglion cells, refractile particles are more in evidence than at three days and variation in Nissl substance distribution is present. At fourteen days the changes noted above are still present although apparently less severe.

At the ultrastructural level at three

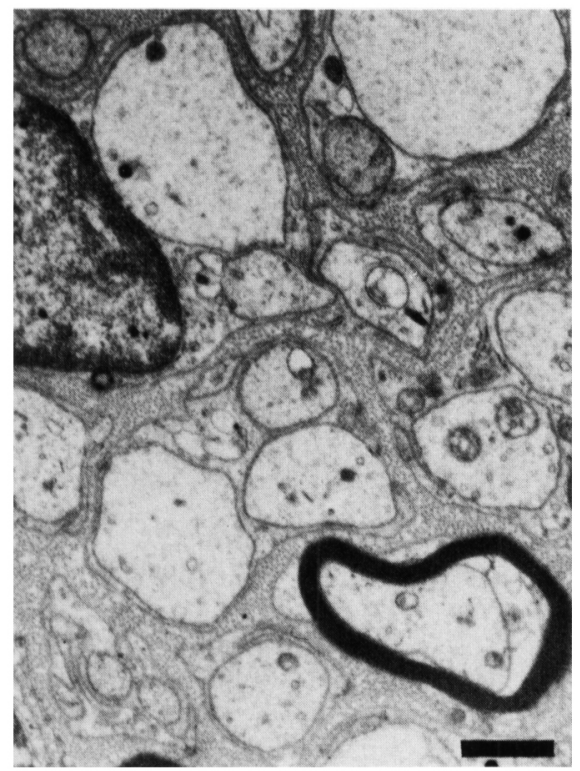

Figurè 7 (b) - Dorsal sympathetic chain of streptozotocin diabetic rat untreated at 14 days after induction of diabetes. Note three larger degenerating axons as well as some smaller regenerating axons - some with long mesaxons. Bar $=1 \mu \mathrm{m}$.

days there is a slight excess of lysosomal bodies, but little other gross change. At seven and fourteen days there is an increase in the numbers of lysosomes and other vesicles and degenerative changes in some mitochondria. Cells undergoing active chromatolysis were not seen at the ultrastructural level.

\section{Myenteric Plexus}

There are no significant changes in the myenteric plexus at three days; however, by seven days occasional axons are swollen and show loss of internal architecture (Figure 9). At fourteen days occasional axons appear to be undergoing degenerative changes, but otherwise the plexus appears normal.

\section{DISCUSSION}

In our earlier paper describing neuropathic changes in the autonomic nervous system in the streptozotocin diabetic rat (Monckton \& Pehowich, 1980) we showed severe degenerative changes in the dorsal sympathetic chain, ganglia, and myenteric plexus. These changes were observed to begin 24 hours following induction of diabetes and were still occurring at six

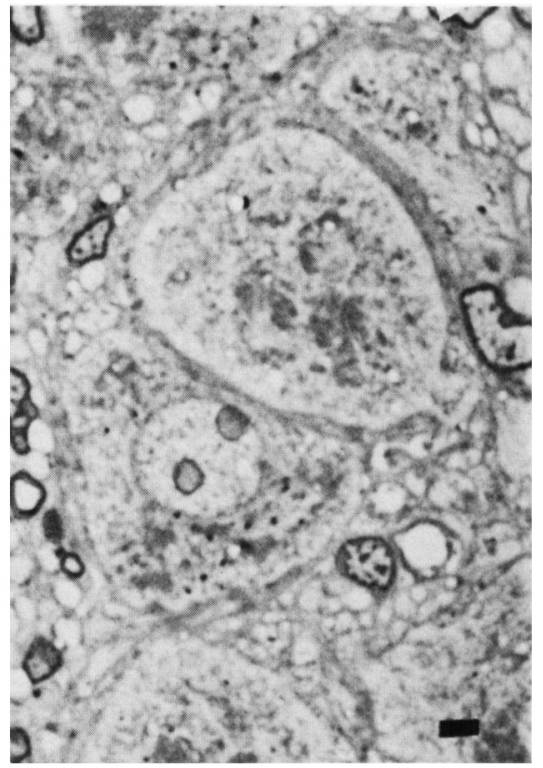

Figure 8 - Dorsal sympathetic ganglion from streptozotocin diabetic rat after seven days treatment. Note eccentric nucleus, two shrunken adjacent chromatolytic nerve cells. $\mathrm{Bar}=1, \mu \mathrm{m}$.

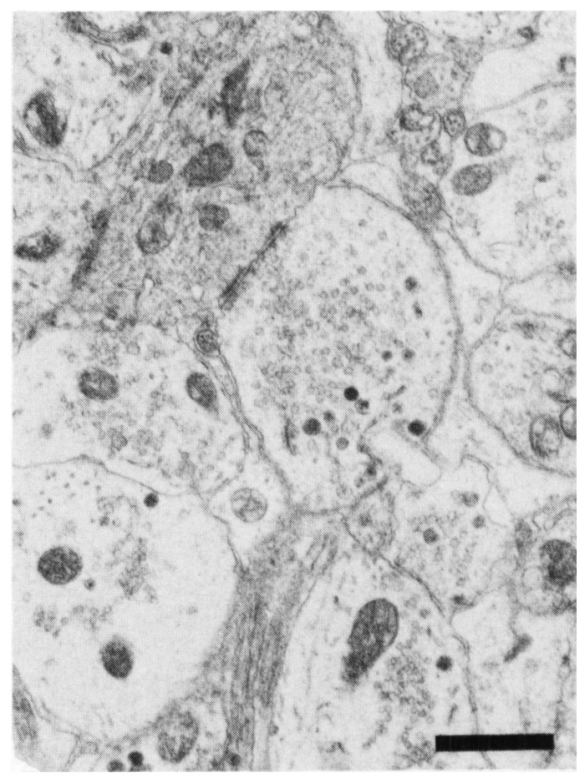

Figure 9 - Myenteric plexus from streptozotocin diabetic rat treated with insulin seven days. A number of small regenerating axons are present as well as swollen featureless axon terminals. $\mathrm{Bar}=1 \mu \mathrm{m}$.

weeks at the termination of our study. However, by two weeks after induction of diabetes evidence of regeneration is present as indicated by the occurrence 
of many small axons of less than 0.4 $\mu \mathrm{m}$ diameter. Thereafter, the ultrastructural appearances were those of continued wallerian degeneration intermixed with increased numbers of regenerating axons. The data presented from the present series of insulin treated streptozotocin diabetic rats show distinct improvement in the ultrastructural appearances of sympathetic ganglia, chain, and myenteric plexuses. This improvement is indicated by the increasing axonal areas of sympathetic chain axons and the early appearance of regenerating axons while degenerating axons become less frequent. Regeneration appears in many axons to be incomplete in that there is a persistent loss of microtubules and an excess of vesicles.

The morphometric studies of the treated and untreated animals in this series raise some interesting questions. At three and seven days in the treated and untreated animals there is a profound shift of the median of axonal areas to the left. This shift is partly due to many small regenerating axons, but is likely also related to either an axonal response to hyperosmolarity or to atrophy. The effect of osmolar changes on neurons has been discussed in detail as it affects myelinated fibers (Dyck et al, 1980; Sugimura et al, 1980). The former authors point out the importance of osmolarity in fixatives in changing appearances in size of axons: The latter correlate osmolar changes in the streptozotocin diabetic rat with the axonal diameter and suggest that shrinkage of axons in the presence of hyperosmolarity is the more probable explanation. These changes are described in myelinated nerve fibers. It seems probable that the relatively small reduction in myelinated axonal fibers in the presence of moderate increases in osmolarity may well be related to the surface area of axons available for rapid fluid exchanges. Thus, in the myelinated axons multiple layers of lipid membrane cover all but the nodal regions and presumably prevent gross response to osmolar changes by providing an effective waterproofing. In the case of nonmyelinated nerve fibers no such barrier exists and one would expect a more profound effect. In a preliminary study (unpublished observations), six pairs of streptozotocin diabetic rats showed mean osmolar changes of approximately 13 milliosmoles above the normal range at three days and that these osmolar changes were associated with a $55 \%$ reduction in axonal diameter. This reduction is quite consistent with the reduced axonal area at three days described in this report. The persistent preponderance of small axons, even though the general axonal architecture appears improved, is consistent with the observed protracted period required for regenerating axons to mature (Dyck \& Hopkins, 1972). The suggestion of atrophy as a cause of the small fibers seems unlikely since the axonal architecture is improved in appearance and the time frame is too short.

At 14 days the histograms seem similar, however, the ultrastructure shows that the majority of the larger fibers in the untreated group are undergoing degeneration. In the treated group, degenerating axons are also seen, but are occasional rather than frequent. At the smaller fiber end of the spectrum the treated group have almost $37 \%$ more fibers of $0.4 \mu \mathrm{m}^{2}$. This appears to indicate a brisker regenerative effort in the treated group.

There remains the problem of relative loss of microtubules in the regenerating axons. In this regard it is important to note that microtubules were well-preserved in the control animals and that fixatives and perfusion techniques were the same for the controls and the diabetic animals. In view of this it would seem less probable that technical factors caused the loss of microtubules. An argument might be made that specific microtubule loss could represent a toxic manifestation of streptozotocin. However, Schein \& Loftus (1968) have defined some of the pharmacokinetics of streptozotocin and show that plasma clearance of this drug in mice is complete in three hours and that with a dosage of $200 \mathrm{mg}$ streptozotocin per $\mathrm{kg}$ there is less than $1 \mathrm{mg}$ metabolites per gram of liver in liver cells after 24 hours. They also demonstrated that the catastrophic effect of this drug on nicotinamide adenine dinucleotide (NAD) is reversed in 48 hours. In view of this rapid clearance of the drug in mice and the recovery of NAD levels, the effects of the drug do not likely persist beyond 48 hours. This being the case, loss of microtubules in regenerating axons is not likely due to streptozotocin. Careful review of the ultrastructure of regenerating axons shows that microtubules become fewer as the axons increase in size (see Figure 7 a) and, in the larger axons, may be absent. Such progressive loss of microtubules suggests a continuing metabolic derangement other than that directly due to the initial ictus of the streptozotocin. The persistence of diabetes and associated changes in osmolarity with fluctuations in blood sugar are more probable causes for the microtubular damage and loss.

In the light of these considerations we feel that the possible effects of streptozotocin in the autonomic nervous system in the rat remain debatable. It is probable that the toxicity of this substance may induce neuropathic changes by the severe reduction of NAD and interference with the redox system as was reported by Gunnarsson et al (1974) and Robbins et al (1980). The former confirmed the effect on NAD reported by Schein \& Loftus (1968) and demonstrated in their studies that the reduction of NAD is associated with reduced nerve conduction velocity. Greene et al (1975) and Palmano et al (1977) also demonstrated that a reduction in myoinositol in whole sciatic nerve and a decrease in phosphatidyl inositol were associated with reduced nerve conduction velocity which could be corrected by myoinositol. This suggests another possible side effect of streptozotocin or diabetes on peripheral nerve axons. Despite these possible causes of the neuropathy in the first place, it seems more probable that the persistence of the neuropathy is related to the associated metabolic changes of the ensuing diabetes. In considering these factors, the metabolic consequences of diabetes, fluctuating hyperglycemia and osmolarity may be of primary importance in preventing full recovery of the neuropathy in partially treated diabetes. The alteration in osmolarity 
may also have an effect on microtubular integrity.

Whatever the underlying basis of the neuropathy, there appears little doubt that compared with the untreated diabetic rat, treatment with intermittent insulin improves the neuronal architecture in the dorsal sympathetic chain and reduces the severity of degeneration present at 14 days after the administration of streptozotocin. Examination of the myenteric plexus also shows a distinct reduction of degenerative changes. The study in our view supports the conclusion that streptozotocin induces both diabetes and a severe autonomic neuropathy, but the subsequent recovery from this is aided by intermittent insulin treatment even if the diabetes is only partially controlled.

\section{REFERENCES}

DYCK, P. J. \& HOPKINS, A. P. (1972) Electron microscopic observations on degeneration and regeneration of unmyelinated fibres. Brain, 95:223-234.

DYCK, P. J., LOW, P. A., SPARKS, M. F., et al (1980) Effect of serum hyperosmolality on morphometry of healthy human sural nerve. Journal of Neuropathology and Experimental Neurology, 39:285-295.
ELIASSON, S. G. (1964) Nerve conduction changes in experimental diabetes. Journal of Clinical Investigation, 43:2353-2358.

ELIASSON, S. G. (1969) Properties of isolated nerve fibres from alloxanized rats. Journal of Neurology, Neurosurgery and Psychiatry, 32:525-529.

GREENE, D. A., DEJESUS, JR., P. V., WINEGRAD, A. I. (1975) Effects of insulin and dietary myoinositol on impaired peripheral motor nerve conduction velocity in acute streptozotocin diabetes. Journal of Clinical Investigation, 55:1326-1336.

GUNNARSSON, R., BERNE, C., AND HELLERSTROM, C. (1974) Cytotoxic effects of streptozotocin and $N$. nitrosometh-ilurea on the pancreatic B cells with special regard to the role of nicotinamide adenine dinucleotide. Biochemical Journal, 140 (3):487-494

JAKOBSEN, J. (1976a) Axonal dwindling in early experimental diabetes. I. A study of cross-sectional nerves. Diabetologia, 12:539-546.

JAKOBSEN, J. (1976b) Axonal dwindling in early experimental diabetes. II. A study of isolated nerve fibres. Diabetologia, 12:547553.

JAKOBSEN, J. (1979) Early and preventable changes of peripheral nerve structure and function in insulin-deficient diabetic rats. Journal of Neurology, Neurosurgery and Psychiatry, 42:509-518.
LUFT, J. H. (196I) Improvements in epoxy resin embedding methods. Journal of Cell Biology, 9:409.

MONCKTON, G. \& PEHOWICH, E. (1980) Autonomic neuropathy in the streptozotocin diabetic rat. Canadian Journal of Neurological Sciences, 7:135-142.

PALMANO, K. P., WHITING, P. H., HAWTHORNE, J. N. (1977) Free and lipid myoinositol in tissues from rats with acute and less severe streptozotocin-induced diabetes. Biochemical Journal, 167:229-235.

ROBBINS, M. J., SHARP, R. A., SLONIM, A. E., \& BURR, I. M. (1980) Protection against streptozotocin-induced diabetes by superoxide dismutase. Diabetologia, 18:5558.

SCHEIN, P. S. \& LOFTUS, S. (1968) Streptozotocin: depression of mouse liver pyridine nucleotides. Cancer Research, 28:15011506.

SENEVIRATNE, K. N. \& PEIRIS, O. A. (1969) The effects of hypoxia on the excitability of the isolated peripheral nerves of alloxar-diabetic rats. Journal of Neurology, Neurosurgery, and Psychiatry, 32:462-469.

SUGIMURA, K., WINDEBANK, A. J., NATARAJAN, V., LAMBERT, E. H., SCHMID, H. H. O., \& DYCK, P. J. (1980) Interstitial hyperosmolarity may cause axis cylinder shrinkage in streptozotocin diabetic nerve. Journal of Neuropathology and Experimental Neurology, 39:710-721. 